\title{
《渔业科学进展》编辑委员会
}

\section{THE EDITORIAL BOARD OF PROGRESS IN FISHERY SCIENCES}

主任 委 员 Chairman 唐启升 TANG Qisheng

副主任委员 Vice-Chairman 麦康森 MAI Kangsen 桂建芳 GUI Jianfang 金显仕 JIN Xianshi

委 员 Editorial Committee (以姓名笔画为序)

$\begin{array}{llll}\text { 王清印 WANG Qingyin } & \text { 王鲁民 WANG Lumin } & \text { 王新鸣 WANG Xinming } & \text { 戈贤平 GE Xianping } \\ \text { 孔 杰 KONG Jie } & \text { 包振民 BAO Zhenmin } & \text { 曲克明 QU Keming } & \text { 任胜民 (新西兰)REN Shengmin } \\ \text { 危起伟 WEI Qiwei } & \text { 庄 平 ZHUANG Ping } & \text { 刘英杰 LIU Yingjie } & \text { 关长涛 GUAN Changtao } \\ \text { 江世贵 JIANG Shigui } & \text { 严小军 YAN Xiaojun } & \text { 李 健 LI Jian } & \text { 李 军 (美国)LI Jun } \\ \text { 李来好 LI Laihao } & \text { 李家乐 LI Jiale } & \text { 李 琪 LI Qi } & \text { 杨红生 YANG Hongsheng } \\ \text { 肖 放 XIAO Fang } & \text { 何建国 HE Jianguo } & \text { 邹桂伟 ZOU Guiwei } & \text { 宋林生 SONG Linsheng } \\ \text { 张士璀 ZHANG Shicui } & \text { 张国范 ZHANG Guofan } & \text { 陈松林 CHEN Songlin } & \text { 陈 勇 (美国)CHEN Yong } \\ \text { 林 洪 LIN Hong } & \text { 岳根华 (新加坡)YUE Genhua } & \text { 周永灿 ZHOU Yongcan } & \text { 赵宪勇 ZHAO Xianyong } \\ \text { 俞志明 YU Zhiming } & \text { 秦 松 QIN Song } & \text { 秦启伟 QIN Qiwei } & \text { 徐 跑 XU Pao } \\ \text { 徐 皓 XU Hao } & \text { 黄 倢 HUANG Jie } & \text { 常亚青 CHANG Yaqing } & \text { 常剑波 CHANG Jianbo } \\ \text { 崔利锋 CUI Lifeng } & \text { 解绶启 XIE Shouqi } & \text { 翟毓秀 ZHAI Yuxiu } & \text { 薛长湖 XUE Changhu }\end{array}$

主编 Editor-in-Chief 金显仕 JIN Xianshi

副主 编 Associate Editor-in-Chief 李 健 LI Jian 孔 杰 KONG Jie

编辑部主任 Editorial Director 常 青 CHANG Qing

渔业科学进展

YUYE KEXUE JINZHAN

（双月刊，1980年创刊）

第 41 卷 第 4 期 2020 年 8 月
PROGRESS IN FISHERY SCIENCES

( Bimonthly, founded in 1980 )

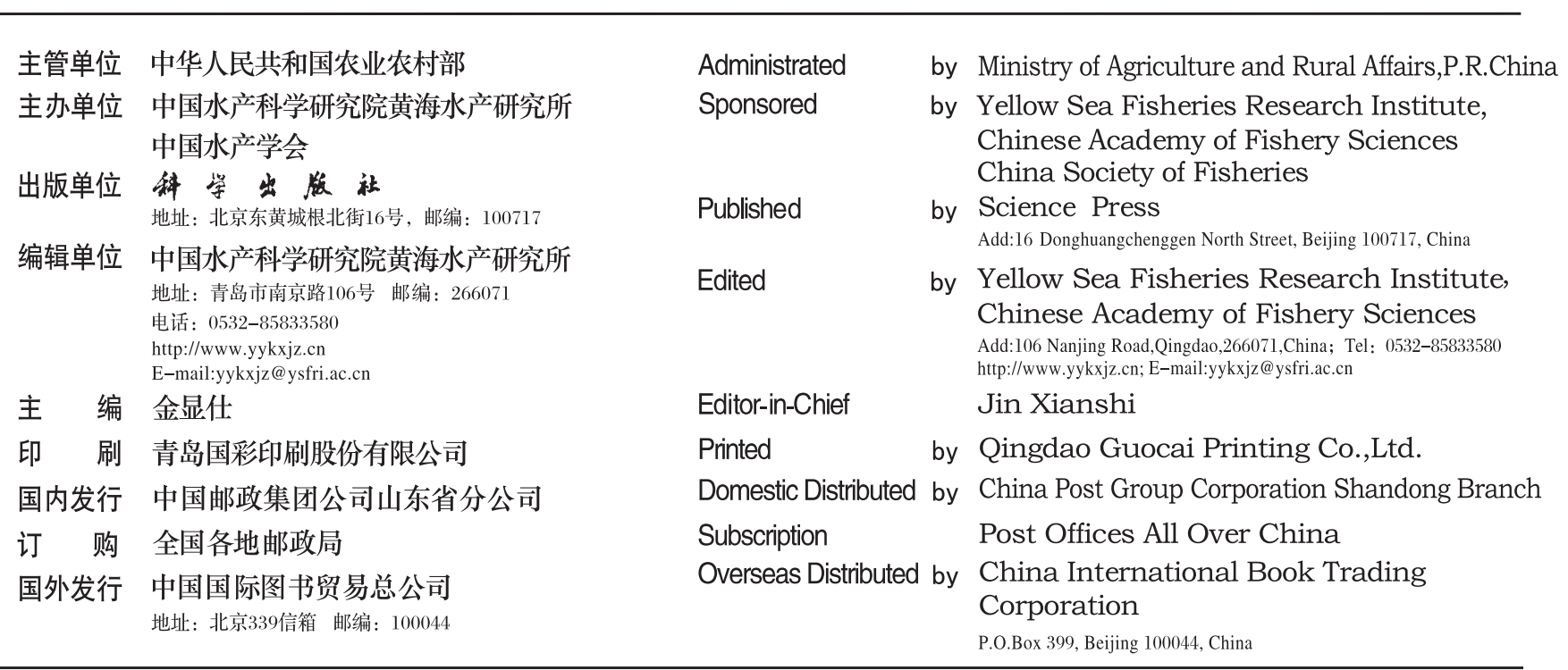

中国标准刊号

ISSN 2095-9869

CN 37-1466/S
国内邮发代号：24-153

国外发行代号：4578Q

国内外公开发行
I S SN 2095-9869

定 价：40.00元

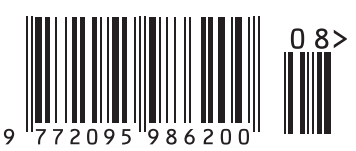

